\title{
Performances of LAD Regression, M-Regression and Quantile Regression Methods in order to Investigate Stock Prices of the Banks in the BIST Bank Index
}

\author{
Umran Munire Kahraman ${ }^{1}$, Neslihan Iyit ${ }^{2}$ \\ ${ }^{1}$ Necmettin Erbakan University, Faculty of Political Sciences, Department of Business Administration, \\ Konya, Turkey \\ ${ }^{2}$ Selcuk University, Faculty of Sciences, Department of Statistics, Alaeddin Keykubat Campus, \\ Konya, Turkey
}

\begin{abstract}
In this study, performances of LAD regression, M-regression, Q25 and Q75 quantile regression models as robust regression methods alternative to the classical LS method are compared in the case of violations from the normality assumption of the error terms and the presence of an outlier. By using these alternative regression methods, stock prices of the 12 commercial banks and 1 participation bank listed in the Istanbul Stock Exchange (BIST) bank index between 2012 and 2016 are investigated in terms of equity size and equity profitability. As a result of this study, M-regression is the most suitable robust regression model with the smallest value of the mean squared error (MSE) measure and the small values for the standard errors of the parameter estimates belonging to the equity size and equity profitability. The smaller the standard errors of the parameter estimates, the narrower the resulting confidence intervals are obtained in $\mathrm{M}$ - regression. The accuracy as a measure of closeness of parameter estimates to the true values of the parameters is also obtained higher in Mregression.
\end{abstract}

Keywords: Stock price, LAD regression, M-regression, Quantile regression, BIST bank index.

\section{Introduction}

In multiple linear regression analysis, parameters are generally estimated by using classical least squares $(L S)$ method. In the $L S$ method, sum of squared errors between the observed and expected values of the dependent variable is minimized as an objective function. In the classical multiple linear regression model, error terms $\varepsilon_{i} ; i=1,2, \ldots, N$ are assumed to be independently and identically distributed with zero mean and $\sigma^{2}$ constant variance $\varepsilon_{i}: N\left(0, \sigma^{2}\right)$. The assumption of "normality" on the error terms is needed for the test of parameters' significances and construction of confidence intervals for the parameters in the multiple linear regression model [23]. The weakness of the $L S$ method is that it is too much influenced from outliers [4].

In the case of violations of the classical multiple linear regression model assumptions [5], [20], [22], especially in the violation of "normality" assumption of the error terms, some robust regression methods such as least absolute deviations $(L A D)$ regression, $M$-regression and

quantile regression are used to model the data. Additionally, in the case of outliers detected in the data structure, the usage of these robust regression methods is recommended alternative to the classical $L S$ method [4], [8]. Some of the studies in the literature on robust regression methods are given as follows;

Juban et al. (2016) used multiple quantile regression approach for energy forecasting in terms of the wind, solar and price tracks in the 2014 Global Energy Forecasting Competition. Jann (2012) evaluated robust regression in Stata in the aspect of efficiency, contamination, breakdown point and generation of robust regression estimators. Al-Qudaimi and Kumar (2017) investigated a new fuzzy regression model based on least absolute deviation method for real life problems. Isabona and Enagbonma (2015) compared the performance of a tuned $L A D$ based Walficsh/Ikegami (W/I) model and $L A D$ regression model according to root mean square error measure. Guimaraes et al. (2017) applied 
complex correntropy similarity measure to complex least mean square, complex recursive least squares and least absolute deviation methods. Kitchenham et al. (2017) reviewed Type I error efficiency and power of statistical tests in robust statistical methods for non-normal data sets in the field of empirical software engineering. Killewald and Bearak (2014) discussed whether the motherhood penalty is larger for low-wage women by using conditional and unconditional multivariate quantile regression methods. Maciejowskaa et al. (2016) obtained forecasted values of electricity spot prices by extending quantile regression averaging approach to factor quantile regression averaging approach for the data from the British power market. Alma (2011) investigated outliers in the linear regression model and compared some of the robust regression methods by a simulation study to determine the best model. Iyit et al. (2011) interpreted the results of the analysis of the meteorological data according to the regions in Turkey between 1999 and 2009 by least squares method and the robust regression methods as $L A D$ regression, $M$ regression and quantile regression. Verardi and Croux (2009) presented effective robust regression estimators and a graphical tool in order to recognize outliers in Stata as a useful guide.

It has always been interesting for researchers and investors to identify accounting variables that affect stock prices. Riffe and Thompson (1998) investigated the relationship between stock prices and accounting variables. They showed that there is a nonlinear relationship between stock price and earnings, book value. Omokhudu and Ibadin (2015) investigated the value relevance of accounting variables on stock prices associated with firm value in the aspect of emerging market context in Nigeria. Glezakos et al. (2012) examined the impact of earnings and book value to the stock prices on 38 companies listed in the Athens Stock Market between 1996 and 2008. Vijitha and Nimalathasan (2014) investigated value relevance of accounting variables and stock price of manufacturing companies in Sri Lanka. Aduda and Chemarum (2010) examined market reaction to the effect of stock splits at the Nairobi Stock Exchange. Macharia and Gatuhi (2013) investigated whether financial performance indicators of the commercial banks in Kenya influenced the market stock prices.

In addition to the studies on robust regression methods and stock price in the literature, performances of $L A D$ regression, $M$-regression, Q25 and Q75 quantile regression models alternative to the classical $L S$ method are compared in the case of violations from the "normality" assumption of the error terms and the presence of an "outlier" in order to investigate "stock prices" of the banks in BIST bank index in terms of "equity size" and "equity profitability".

\section{Material and Methods}

In this section, firstly multiple linear regression with the classical $L S$ method and then $L A D$ regression, $M$-regression and quantile regression as robust regression methods in the case of violations from the "normality" assumption of the error terms and the presence of an "outlier" will be introduced. As material in this study, stock prices, equity sizes and equity profitabilities of the 12 commercial banks and 1 participation bank listed in Istanbul Stock Exchange (BIST) bank index [21] between 2012 and 2016 are used. By using the above mentioned regression methods, stock prices of these banks between 2012 and 2016 are investigated in terms of equity size and equity profitability.

\subsection{Least Squares Method}

The multiple linear regression model reveals the linear relationship between independent variables and the dependent variable [26]. If the assumptions of the multiple linear regression model are satisfied, regression parameters are estimated by using least squares $(L S)$ method. In case there are $p$ numbers of independent variables, the multiple linear regression model is given as follows;

$Y_{i}=\beta_{0}+\beta_{1} X_{i 1}+\beta_{2} X_{i 2}+\ldots+\beta_{p} X_{i p}+\varepsilon_{i}, \quad i=1 \mathrm{~K}, N$

where $\varepsilon_{i}$ are the random error terms independently and identically distributed with zero mean and $\sigma^{2}$ constant variance $\varepsilon_{i}: N\left(0, \sigma^{2}\right)$ [23]. In the $L S$ method, sum of squared residuals between the observed and expected values of the dependent variable is minimized as an objective function $\min \left(\sum_{i=1}^{n} e_{i}^{2}\right)$ where $e_{i}=y_{i}-\hat{y}_{i}$ are the residual terms.

The assumptions on the error terms in the multiple linear regression model are investigated by using the residuals belonging to the model [28].

The statistical significance of the regression parameters in the multiple linear regression model is tested under the following null hypothesis; 


$$
\begin{aligned}
& H_{0}: \beta_{j}=0 \\
& H_{1}: \beta_{j} \neq 0
\end{aligned} ; j=0,1,2, \ldots, p
$$

with the following test statistic [23];

$$
t=\frac{\hat{\beta}_{j}}{\text { s.e. }\left(\hat{\beta}_{j}\right)}
$$

In case residuals are not normally distributed or outliers in the data structure are observed, parameter estimates according to the $L S$ method lose their effectiveness [4]. Additionally, independent variables in the multiple linear regression model should not be correlated. In this section, in case of violations of the assumptions of multiple linear regression model or presence of outliers in the data structure, some robust methods such as least absolute deviations ( $L A D)$ regression, $M$-regression and quantile regression will be introduced.

\subsection{Least Absolute Deviations Regression}

In the least absolute deviations ( $L A D)$ regression method, sum of the absolute values of the residuals is minimized as an objective function $\min \left(\sum_{i=1}^{n}\left|e_{i}\right|\right)$ where $e_{i}=y_{i}-\hat{y}_{i}$ are the residual terms in order to find the parameter estimates of $\underline{\boldsymbol{\beta}}=\left(\beta_{0}, \beta_{1}, \ldots, \beta_{\mathrm{p}}\right)^{\prime}$ in Eq.(1) [26]. In other words, there have to be solved the optimization problem given below;

$$
\min \sum_{i=1}^{n}\left|Y_{i}-\left(\beta_{0}+\beta_{1} X_{i 1}+\beta_{2} X_{i 2}+\ldots+\beta_{p} X_{i p}\right)\right|
$$

Birkes and Dodge (1993) offered an algorithm in order to estimate the regression parameters based on Eq.(4) by the $L A D$ method.

The statistical significance of the regression parameters in the $L A D$ method is tested under the null hypothesis given in Eq.(2) with the test statistic given in Eq.(3) [4].

\section{3. $M$-Regression}

In the $M$-regression method, Huber's $M$-estimator [9], [10] is used. In Huber's M-estimator, $\rho(e)$ function is defined as follows [4];

$$
\rho(e)=\left\{\begin{array}{ccc}
\frac{1}{2} e^{2} & \text { if } & -\mathrm{c} \leq \mathrm{e} \leq \mathrm{c} \\
\mathrm{c}|\mathrm{e}|-\frac{1}{2} \mathrm{c}^{2} & \text { if } & \mathrm{e}<-\mathrm{c} \text { or } \mathrm{c}<\mathrm{e}
\end{array}\right.
$$

where $c$ is taken as 1.345 [26]. The $L S$ and the $L A D$ regression parameter estimators are the special cases of the $M$-regression parameter estimator in case of $\rho(\mathrm{e})=\mathrm{e}^{2}$ and $\rho(\mathrm{e})=|\mathrm{e}|$, respectively.

In the $M$-regression method, sum of the functions $\rho\left(\mathrm{e}_{\mathrm{i}}\right)$ of the error terms $e_{i}=y_{i}-\hat{y}_{i}$ is minimized as an objective function;

$$
\sum_{\mathrm{i}=1}^{\mathrm{n}} \rho\left(\mathrm{e}_{\mathrm{i}}\right)=\sum_{\mathrm{i}=1}^{\mathrm{n}} \rho\left(\mathrm{Y}_{\mathrm{i}}-\left(\beta_{0}+\beta_{1} \mathrm{X}_{\mathrm{i} 1}+\beta_{2} \mathrm{X}_{\mathrm{i} 2}+\ldots+\beta_{\mathrm{p}} \mathrm{X}_{\mathrm{ip}}\right)\right)
$$

to find the parameter estimates of $\underline{\boldsymbol{\beta}}=\left(\beta_{0}, \beta_{1}, \ldots, \beta_{\mathrm{p}}\right)^{\prime}$ in Eq.(1). The initial values for the parameter estimates in $M$-regression are firstly derived by using the $L S$ method. These values are employed to find the errors used to determine improved estimates of the $M$-regression parameters. The algorithm continues until the improved estimates of the $M$-regression parameters are the same with or very close to the previous step [4]. The statistical significance of the regression parameters in the $M$-regression method is tested as in the $L S$ method.

\subsection{Quantile Regression}

The $k^{\text {th }}$ quantile of a cumulative distribution function $F$ is the minimum of the set of values $Y$ such that $\mathrm{F}(\mathrm{Y}) \geq \mathrm{k}$. The function $\mathrm{Q}^{\mathrm{k}}$ is then referred to as the quantile function of $F$.

For any $\mathrm{k} \in(0,1)$, the distance from $Y$ to a given $q$ is measured by the absolute distance between them as follows [8];

$$
\mathrm{d}_{\mathrm{k}}(\mathrm{Y}, \mathrm{q})= \begin{cases}(1-\mathrm{k})|\mathrm{Y}-\mathrm{q}| & ; \mathrm{Y}<\mathrm{q} \\ \mathrm{k}|\mathrm{Y}-\mathrm{q}| ; & \mathrm{Y} \geq \mathrm{q}\end{cases}
$$

Quantile regression model can be expressed for the $k^{\text {th }}$ quantile as follows;

$$
Y_{i}=\beta_{0}^{(k)}+\beta_{1}^{(k)} X_{i 1}+\beta_{2}^{(k)} X_{i 2}+\ldots+\beta_{p}^{(k)} X_{i p}+\varepsilon_{i}^{(k)}, \quad i=1 \mathrm{~K}, n
$$

where $0<\mathrm{k}<1$ indicates the proportion of the population having scores below the $k^{\text {th }}$ quantile. In the quantile regression method, for the $k^{\text {th }}$ quantile, sum of the distances from the observed values to the expected values of the dependent variable is minimized as an objective function as follows;

$$
\begin{aligned}
\sum_{\mathrm{i}=1}^{\mathrm{n}} \mathrm{d}_{\mathrm{k}}\left(\mathrm{Y}_{\mathrm{i}}, \hat{Y}_{\mathrm{i}}\right)= & \mathrm{k} \sum_{\mathrm{i}=1}^{\mathrm{n}} \mathrm{Y}_{\mathrm{i}}>\beta_{0}^{(k)}+\beta_{1}^{(k)} X_{\mathrm{i} 1}+\beta_{2}^{(k)} X_{\mathrm{i} 2}+\ldots+\beta_{\mathrm{p}}^{(k)} X_{\mathrm{ip}} \\
& \left|Y_{\mathrm{i}}-\left(\beta_{0}^{(k)}+\beta_{1}^{(k)} X_{\mathrm{i} 1}+\beta_{2}^{(k)} X_{\mathrm{i} 2}+\ldots+\beta_{\mathrm{p}}^{(k)} X_{\mathrm{ip}}\right)\right| \\
& +(1-\mathrm{k}) \sum_{\mathrm{i}=1}^{\mathrm{n}} \mathrm{Y}_{\mathrm{i}}<\beta_{0}^{(k)}+\beta_{1}^{(k)} X_{\mathrm{i} 1}+\beta_{2}^{(k)} X_{\mathrm{i} 2}+\ldots+\beta_{\mathrm{p}}^{(k)} X_{\mathrm{ip}} \\
& \left|\mathrm{Y}_{\mathrm{i}}-\left(\beta_{0}^{(k)}+\beta_{1}^{(k)} X_{\mathrm{i} 1}+\beta_{2}^{(k)} X_{\mathrm{i} 2}+\ldots+\beta_{\mathrm{p}}^{(k)} X_{\mathrm{ip}}\right)\right|
\end{aligned}
$$

where $d_{k}$ is the distance in Eq.(7) [8]. 
In order to test the statistical significance of the regression parameters in the quantile regression method for the $k^{\text {th }}$ quantile;

$$
\begin{aligned}
& H_{0}: \beta_{j}^{(k)}=0 \\
& H_{1}: \beta_{j}^{(k)} \neq 0
\end{aligned} ; j=0,1,2, \ldots, p
$$

$t$-test statistic is used for the $k^{\text {th }}$ quantile as follows;

$t=\frac{\hat{\beta}_{j}^{(k)}}{\text { s.e. }\left(\hat{\beta}_{j}^{(k)}\right)}$

Since the error terms $\varepsilon_{i}^{(k)}$ cannot be independent and identically distributed, Bootstrap method as a robust technique that does not require distribution assumption can be used to calculate standard errors of the parameter estimates in Eq.(11) [8].

\section{Results and Discussion}

In order to compare the performances of the $L A D$ regression, $M$-regression and quantile regression alternative methods to the $L S$ method in regression analysis, it has been researched whether equity size and equity profitability are effective in forming stock prices of banks. In accordance with this purpose, stock price is taken as dependent variable, equity size and equity profitability are taken as independent variables belonging to the 12 commercial banks and 1 participation bank listed in Istanbul Stock Exchange (BIST) BANK index [21] between 2012 and 2016. As the equity size variable consists of high values compared to stock price and equity profitability variables, equity size is transformed to $\log$ (equity size) by taking logarithm to get more stabilized parameter estimates by using alternative regression methods. All statistical computations are done by using Microsoft Excel, Minitab 17 and Stata 14 statistical softwares. Descriptive statistics belonging to the accounting variables used in this study are demonstrated in Table 1.

Table 1: Descriptive statistics belonging to the accounting variables used in this study

\begin{tabular}{cllllll} 
Variables & $\begin{array}{l}\text { Number } \\
\text { of } \\
\text { observations }\end{array}$ & $\begin{array}{c}\text { Minimu } \\
\mathbf{m}\end{array}$ & $\mathbf{m}^{\text {Maximu }}$ & Mea & $\begin{array}{l}\text { Standar } \\
\mathbf{d} \\
\text { deviatio } \\
\text { n }\end{array}$ \\
\hline Stock price & 65 & 1.2 & 19.55 & 5.495 & 3.753 \\
$\begin{array}{l}\text { Equity size } \\
\text { Equity }\end{array}$ & 65 & 5.76 & 7.62 & 6.805 & 0.597 \\
profitability & 65 & -0.02 & 0.34 & 0.149 & 0.066 \\
\hline
\end{tabular}

In order to test the validity of the multiple linear regression model by using the classical $L S$ method, the "normality" assumption of the residuals and the presence of "multicollinearity" and "outlier" in the data structure are examined. In $P-P$ graph, residuals examined on the line or close to the line shows that the "normality" assumption of the residuals is satisfied. As it is seen from Figure 1, residuals obtained by the $L S$ method demonstrate deviations from normality. Additionally, as a result of the Anderson-Darling $(A D)$ goodness-of-fit test [24], the value of the $A D$ test statistic is found to be 1.973 and the null hypothesis that "The distribution of the residuals comes from the normal distribution" is rejected with statistically significant $p$-value $<0.005$ at $\alpha=0.05$ significance level.

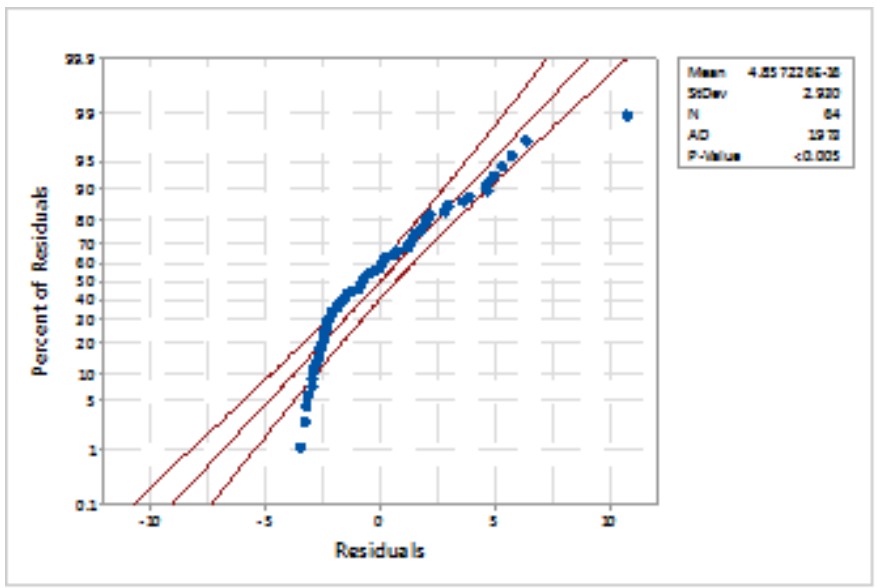

Figure 1: $P-P$ graph for testing normality of the residuals by the $L S$ method

In order to detect whether there is a multicollinearity problem between equity size and equity profitability independent variables, variance inflation factor $(V I F)$ value is found to be 1.22 and 
it shows that the data structure has no multicollinearity problem.

In order to determine whether there is an outlier in the data structure, the scatterplot of the order of observations versus Cook's distance as a regression diagnostic is given in Figure 2. As it is seen from Figure 2, 40 ${ }^{\text {th }}$ ordered observation is found to be an outlier in the dataset.

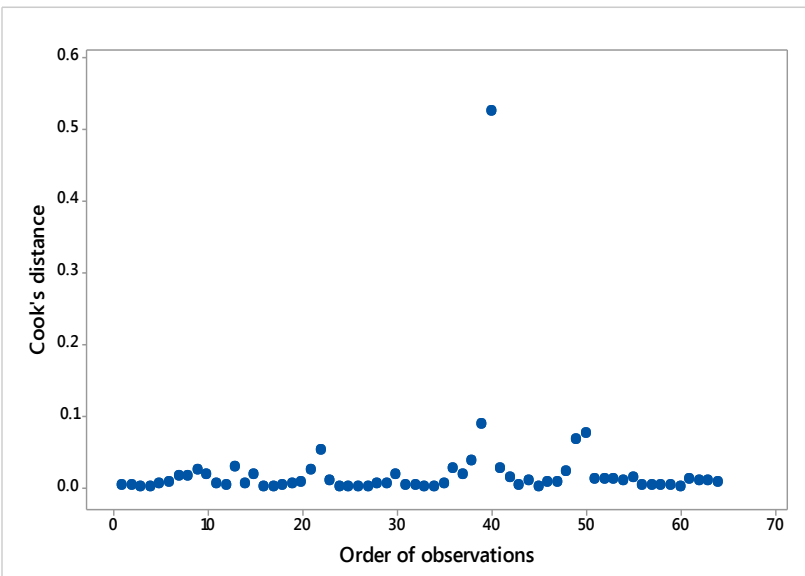

In the case of violations from the "normality" assumption of the error terms and the presence of an "outlier" in the dataset, some robust regression methods such as $L A D$ regression, $M$-regression and quantile regression are used to estimate regression parameters. Results for these robust regression methods against the classical $L S$ method are given in Table 2 in terms of parameter estimates, standard errors of the parameter estimates, $t$-test statistic and related significance values, lower and upper limits for the 95\% confidence interval. Results for the $L A D$ regression called median regression or $Q 50$ quantile regression and also Q25 and Q75 quantile regressions are obtained by using Quantile Regression Module in Stata 14 statistical software. The results for the $M$-regression are obtained by using robreg command [13] in Stata 14 statistical software.

Figure 2: Scatterplot of the order of observations versus Cook's distance

Table 2: Results for some robust regression methods and the classical $L S$ method for the stock price data belonging to the 13 banks listed in the BIST bank index

\begin{tabular}{|c|c|c|c|c|c|c|c|}
\hline & & & & & & $\begin{array}{c}95 \% \\
\text { interval }\end{array}$ & confidence \\
\hline Method & Variables & $\hat{\beta}$ & s.e. $(\hat{\beta})$ & $\begin{array}{l}t \text {-test } \\
\text { statistic }\end{array}$ & Sig. & $r^{\text {Lowe }}$ & Upper \\
\hline \multirow{3}{*}{$L S$ method } & Constant & -15.8696 & 4.3593 & -3.64 & $0.001 *$ & -24.5838 & -7.1554 \\
\hline & Equity size & 2.7628 & 0.6839 & 4.04 & $0.000 *$ & 1.3956 & 4.1301 \\
\hline & Equity profit. & 17.2419 & 6.2009 & 2.78 & $0.007 *$ & 4.8464 & 29.6374 \\
\hline \multirow{3}{*}{$\begin{array}{l}L A D \\
\text { regression }\end{array}$} & Constant & -17.8225 & 5.8492 & -3.05 & $0.003^{*}$ & -29.5148 & -6.1301 \\
\hline & Equity size & 3.0235 & 0.9177 & 3.29 & $0.002 *$ & 1.1889 & 4.8580 \\
\hline & Equity profit. & 12.7055 & 8.3202 & 1.53 & 0.132 & -3.9263 & 29.3375 \\
\hline \multirow{3}{*}{$M$-regression } & Constant & -16.4438 & 3.7269 & -4.41 & $0.000 *$ & -23.7484 & -9.1392 \\
\hline & Equity size & 2.9339 & 0.5645 & 5.20 & $0.000 *$ & 1.8273 & 4.0404 \\
\hline & Equity profit. & 10.8172 & 4.6013 & 2.35 & $0.019 *$ & 1.7988 & 19.8355 \\
\hline \multirow{3}{*}{$\begin{array}{l}Q 25 \text { quantile } \\
\text { regression }\end{array}$} & Constant & -16.5959 & 2.0642 & -8.04 & $0.000^{*}$ & 20.7223 & -12.4695 \\
\hline & Equity size & 2.8269 & 0.3239 & 8.73 & $0.000 *$ & 2.1794 & 3.4743 \\
\hline & Equity profit. & 3.5721 & 2.9363 & 1.22 & 0.228 & -2.2976 & 9.4417 \\
\hline \multirow{3}{*}{$\begin{array}{l}Q 75 \text { quantile } \\
\text { regression }\end{array}$} & Constant & -12.0129 & 8.7724 & -1.37 & 0.176 & -29.5487 & 5.5229 \\
\hline & Equity size & 2.4653 & 1.3764 & 1.79 & 0.078 & -0.2860 & 5.2166 \\
\hline & Equity profit. & 15.1022 & 12.4784 & 1.21 & 0.231 & -9.8417 & 40.0462 \\
\hline
\end{tabular}

Mean squared error (MSE) values as a measure of estimators' precision (variance) and accuracy (bias) in the classical $L S$ method, $L A D$ regression, $M$-regression, $Q 25$ and $Q 75$ quantile regressions in Table 2 are found to be 8.753, 9.152, 0.928, 2.199 and 10.984, respectively. In terms of MSE, $M$ - regression is most preferred among the mentioned robust methods against to the $L S$ method. By

taking advantage of the parameter estimates belonging to the $M$-regression given in Table 2, $M$-regression model equation can be written as follows; 
stock price $_{\mathrm{i}}=-16.4438+2.9339 \log (\text { equitysize })_{\mathrm{i}}$

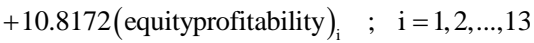

belonging to the 12 commercial banks and 1 participation bank listed in the Istanbul Stock Exchange (BIST) bank index. As it is seen from Eq.(12), one unit increase in both of the equity size and the equity profitability have positive effects as

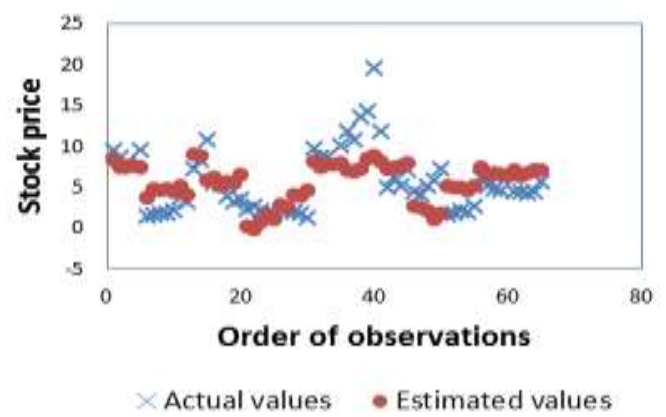

2.9339 and 10.8172 units on the stock prices of these banks, respectively.

In Figure 3, scatterplots of the actual versus estimated values of the stock prices of the 13 banks listed in the BIST bank index by the classical LS method and the alternative robust regression methods mentioned above are given in order to investigate how estimated values are close to the actual ones visually.

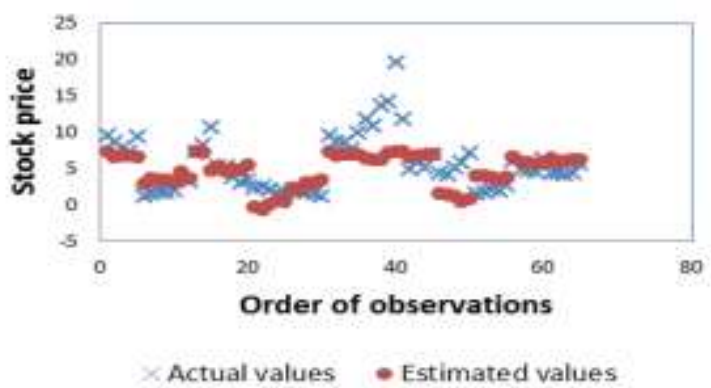

Figure 3.a: Actual versus estimated values of the stock prices of the 13 banks listed in the BIST bank index by $L S$ method and $L A D$ regression
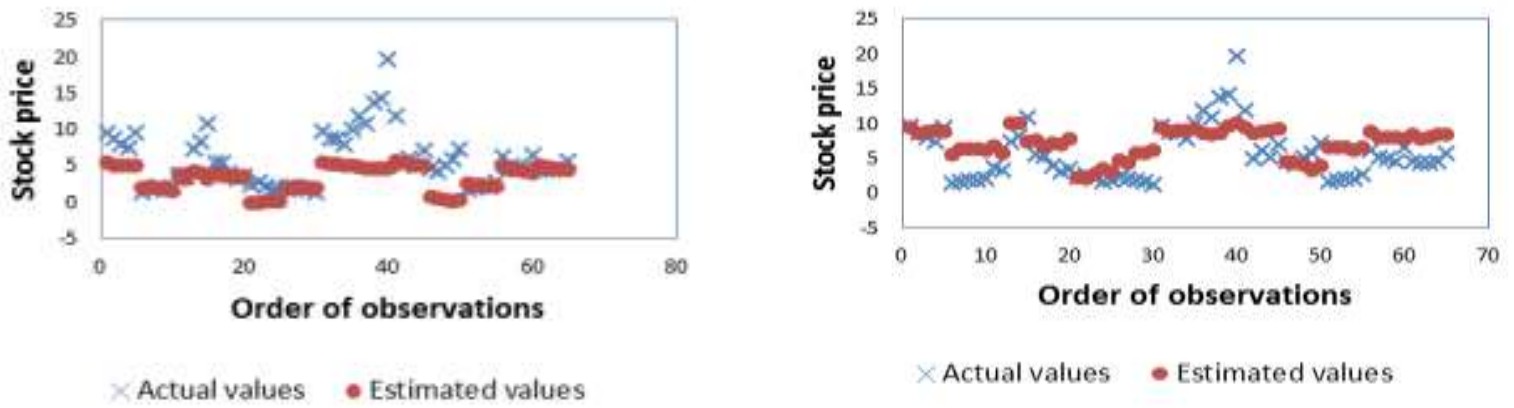

Figure 3.b: Actual versus estimated values of the stock prices of the 13 banks listed in the BIST bank index by $Q 25$ and $Q 75$ quantile regression methods

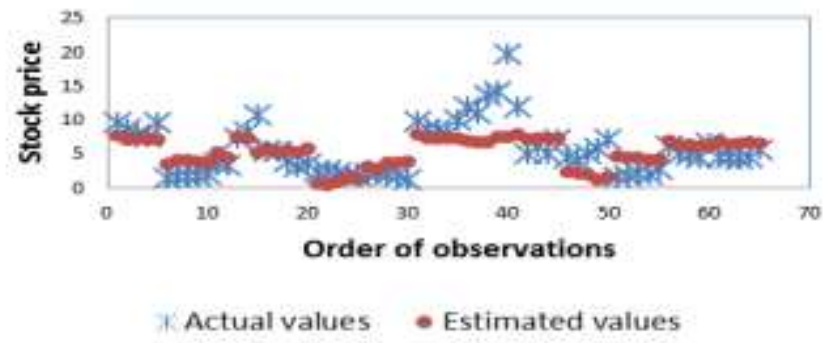

Figure 3.c: Actual versus estimated values of the stock prices of the 13 banks listed in the BIST bank index by $M$-regression

\section{Conclusions}

In this study, performances of $L A D$ regression, $M$ regression, $Q 25$ and $Q 75$ quantile regression models alternative to the classical $L S$ method are compared in the case of violations from the "normality" assumption of the error terms and the presence of an "outlier" in order to investigate stock prices of the 13 banks listed in the BIST bank index in terms of equity size and equity profitability.

According to this comparison between the alternative robust regression methods mentioned above and the classical $L S$ method;

Q75 quantile regression model is the most unsuitable regression model with respect to the high standard errors of the parameter estimates given in Table 2 and the highest value of the MSE measure. 
On the other hand, $M$-regression model is the most suitable regression model with the smallest value of the MSE measure and the small values for the standard errors of the parameter estimates belonging to the equity size and equity profitability. The only disadvantage of this method is the tolerable high standard error of the parameter estimate belonging to the statistically significant equity profitability variable.

Q25 quantile regression model could be a suitable regression model for the dataset in terms of the small value of the MSE measure. On the other hand, the standard error of the parameter estimate belonging to the equity profitability variable is obtained too high according to its parameter estimate and this situation makes this variable statistically insignificant.

$L A D$ regression model has the second highest $M S E$ value also with the high standard error of the parameter estimate belonging to the equity profitability variable making statistically insignificant.

In the classical $L S$ method, equity size and equity profitability are also obtained as statistically significant variables as in $M$-regression. On the other hand, the $L S$ method against to the robust regression methods has the third highest $M S E$ value among the mentioned alternative regression models. The high value of this measure is an important disadvantage for modelling the data by the classical $L S$ method. Additionally, it is not appropriate to use this method since the "normality" assumption of the error terms is not satisfied.

The narrowest $95 \%$ confidence interval for the equity size statistically significant variable is obtained in $Q 25$ quantile regression model. The second narrowest $95 \%$ confidence interval for this variable is obtained in $M$-regression model. Also the narrowest $95 \%$ confidence interval for the equity profitability statistically significant variable is obtained in $M$-regression model. Thus, the smaller the standard errors of the parameter estimates, the narrower the resulting confidence intervals are obtained in $M$-regression model. Therefore, the accuracy as a measure of closeness of the parameter estimates to the true values of the parameters is obtained higher in $M$ regression model.

\section{Acknowledgements}

Neslihan Iyit is the "main author" of this study. The authors would like to thank the editor and the reviewers in the improvement of this study. The authors received no funding support in this study.

Conflict of interest: The authors declare that there is no conflict of interest.

\section{References}

[1]J. Aduda, C. Chemarum, "Market Reaction to Stock Splits: Empirical Evidence from the Nairobi Stock Exchange", African Journal of Business \& Management, Vol. 1, pp. 165-184, 2010.

[2]O.G. Alma, "Comparison of Robust Regression Methods in Linear Regression", Int. J. Contemp. Math. Sciences, 6(9), pp. 409-421, 2011.

[3]A. Al-Qudaimi, A. Kumar, "A note on "A new fuzzy regression model based on absolute deviation",", Engineering Applications of Artificial Intelligence, 66, pp. 30-32, 2017.

[4]D. Birkes, Y. Dodge, Alternative Methods of Regression, John Wiley \& Sons, Inc., USA, 1993.

[5]J. Cohen, P. Cohen, S.G. West, L.S. Aiken, Applied Multiple Regression/Correlation Analysis for the Behavioral Sciences, Third Edition, Lawrence Erlbaum Associates, Publishers, London, UK, 2003.

[6]M. Glezakos, J. Miylonakis, C. Kafouros, "The Impact of Accounting Information on Stock Prices: Evidence from the Athens Stock Exchange", International Journal of Economics and Finance, 4(2), pp. 56-68, 2012.

[7]J.P.F. Guimaraes, A.I.R. Fontes, J.B.A. Rego, A.M. Martins, J.C. Principe, "Complex Correntropy Function: properties, and application to a channel equalization problem", Expert System with Applications (in press). Available: https://arxiv.org/pdf/1710.00081.pdf. [Accessed: Sep. 29, 2017].

[8]L. Hao, D.Q. Naiman, Quantile Regression, Sage Publicaitons, Inc., USA, 2007.

[9]P.J. Huber, "Robust Estimation of a Location Parameter", The Annals of Mathematical Statistics, 35(1), pp. 73-101, 1964. 
[10] P.J. Huber, "Robust Regression: Asymptotics, Conjectures and Monte Carlo", The Annals of Statistics, 1(5), pp. 799-821, 1973.

[11] J. Isabona, O. Enagbonma, "A Least Absolute Deviation Tuning Method to Reduce Signal Coverage Loss Prediction Error in Electromagnetic Wave Propagation Channel", BIU Journal of Basic and Applied Sciences, 1(1), pp. 26-39, 2015.

[12] N. Iyit, U.M. Teksen, I. Altindag, "Comparison of Some Robust Methods in Regression Analysis", 24th International Conference of Jangjeon Mathematical Society, 20-23 July 2011, Konya, Turkey.

[13] B. Jann, "Robust Regression in Stata", 2012. Available:

https://www.stata.com/meeting/germany12/abst racts/desug12 jann.pdf. [Accessed: Nov. 9, 2017].

[14] R. Juban, H. Ohlsson, M. Maasoumya, L. Poirier, J.Z. Kolter, "A multiple quantile regression approach to the wind, solar, and price tracks of GEFCom2014", International Journal of Forecasting, 32, pp. 1094-1102, 2016.

[15] A. Killewald, J. Bearak, Is the Motherhood Penalty Larger for Low-Wage Women? A Comment on Quantile Regression, American Sociological Review, 79(2), pp. 350-357, 2014.

[16] B. Kitchenham, L. Madeyski, D. Budgen, J. Keung, P. Brereton, S. Charters, S. Gibbs, A. Pohthong, "Robust Statistical Methods for Empirical Software Engineering”, Empirical Software Engineering, 22, pp. 579-630, 2017.

[17] P. Macharia, S. Gatuhi, "Effect of Financial Performance Indicators on Market Price of Shares in Commercial Banks of Kenya", International Journal of Management \& Business Studies, 3(3), pp. 57-60, 2013.

[18] K. Maciejowskaa, J. Nowotarski, R. Werona, "Probabilistic forecasting of electricity spot prices using Factor Quantile Regression Averaging", International Journal of Forecasting, 32, pp. 957-965, 2016.

[19] O.O. Omokhudu, P.O. Ibadin, "The Value Relevance of Accounting Information: Evidence from Nigeria", Accounting and Finance Research, 4(3), pp. 20-30, 2015.

[20] M.A. Poole, P.N. O'Farrell, "The Assumptions of the Linear Regression Model", Transactions of the Institute of British Geographers, 52, pp.145-158, 1971.
[21] Public Disclosure Platform, Available: https://www.kap.org.tr/en/. [Accessed: Nov. 9, 2017].

[22] C.R. Rao, H. Toutenburg, Linear Models: Least Squares and Alternatives, Second Edition, Springer-Verlag, Inc., New York, 1999.

[23] J.O. Rawlings, S.G. Pantula, D.A. Dickey, Applied Regression Analysis: A Research Tool, Springer, New York, USA, 1998.

[24] N.M. Razali, B.W. Yap, "Power comparisons of Shapiro-Wilk, Kolmogorov-Smirnov, Lilliefors and Anderson-Darling tests", Journal of Statistical Modeling and Analytics, 2(1), pp. 21-33, 2011.

[25] S. Riffe, R. Thompson, "The Relation between Stock Prices and Accounting Information", Review of Accounting Studies, 2, pp. 325-351, 1998.

[26] V. Verardi, C. Croux, "Robust Regression in Stata", The Stata Journal, 9(3), pp. 439-453, 2009.

[27] P. Vijitha, B. Nimalathasan, "Value relevance of accounting information and share price: A study of listed manufacturing companies in Sri Lanka", Merit Research Journal of Business and Management, 2(1), pp. 1-6, 2014.

[28] S. Weisberg, Applied Linear Regression, John Wiley \& Sons, Inc., USA, 2005.

\section{Author Profile}

Umran Munire Kahraman received the B.S. degree in Business Administration Department from Selcuk University in 2005, M.Sc. degree in Statistics Department from Selcuk University in 2008 and Ph.D. degree in Statistics Department from Selcuk University 2012, respectively. She has been working as an assistant professor doctor at Necmettin Erbakan University, Turkey since 2014. Her research interests are applied statistics, time series, and panel data analysis.

Neslihan Iyit received the B.S. degree in Statistics Department from Dokuz Eylul University in 2000, M.Sc. degree in Statistics Department from Selcuk University in 2003 and Ph.D. degree in Mathematics Department from Selcuk University 2008, respectively. She has been working as an assistant professor doctor at Selcuk University, Turkey since 2011. Her research interests are applied statistics, statistical modelling techniques, categorical data analysis, linear mixed models, generalized linear models and generalized estimating equations. 